\title{
Quality Improvement and Patient Safety Education in Internal Medicine Residency Training Program: An Exploratory Qualitative Study
}

\author{
Ali Al Qarni ${ }^{1-3}$ \\ Sami Al-Nasser ${ }^{4,5}$ \\ Abdullah Alzahem ${ }^{4-6}$ \\ Tarig Awad Mohamed ${ }^{4,5}$ \\ 'Endocrinology and Metabolism, \\ Department of Medicine, King Abdulaziz \\ Hospital, Ministry of National Guard \\ Health Affairs, Al Ahsa, Saudi Arabia; \\ ${ }^{2}$ King Abdullah International Medical \\ Research Center, Al Ahsa, Saudi Arabia; \\ ${ }^{3}$ King Saud bin Abdulaziz University for \\ Health Sciences, Al Ahsa, Saudi Arabia; \\ ${ }^{4}$ Department of Medical Education, \\ College of Medicine, King Saud bin \\ Abdulaziz University for Health Sciences, \\ Riaydh, Saudi Arabia; ${ }^{5}$ King Abdullah \\ International Medical Research Center, \\ Riyadh, Saudi Arabia; ${ }^{6}$ Department of \\ Dental Services, King Abdulaziz Medical \\ City, Ministry of National Guard Health \\ Affairs, Riyadh, Saudi Arabia
}

Background: Quality improvement and patient safety (QIPS) are a global health priority. Accordingly, QIPS education in medical education became mandatory. Despite that, information about QIPS education in postgraduate training in Saudi Arabia is limited. This study aimed to explore the educational aspects of QIPS in the internal medicine residency training program at King Abdulaziz Hospital in Al Ahsa, Saudi Arabia.

Methods: This was a qualitative study employing the constructivist grounded theory approach. The sample size was determined using the theoretical saturation point, and we utilized a purposeful sampling technique. A semi-structured interview was used for data collection and was conducted between September 6 and October 20, 2020.

Results: Twenty-two internal medicine trainee residents were required to serve the study purpose. The emerged themes were organized under awareness, education, barriers and opportunities and improvement priorities. Awareness of participants about the QIPS concept, importance, and value of education was found. The participants did not recognize specific dedicated QIPS education components under the structured training program. However, they recognized participation in patient safety-oriented activities but not in quality improvement activities. Consultants' observations and written exams were perceived as the assessment tools. Barriers including time limitation and opportunities including participation in quality improvement projects were identified. Participants suggested making QIPS education mandatory under the training program as an improvement priority.

Conclusion: This study highlighted the awareness of internal medicine residents of the QIPS concept, importance, and value of QIPS education. However, we found crucial gaps related to education including lack of a dedicated QIPS component under the training program. There is a need for multicenter studies to measure the magnitude of our findings for improvement of QIPS education in residency training in Saudi Arabia. This is the first study about QIPS education in residency training in Saudi Arabia up to our best knowledge. Keywords: quality improvement and patient safety, QIPS, internal medicine residency training program, QIPS curriculum

\section{Introduction}

Quality in health care is "the delivery of the right care to the right patient at the right place and time with the right resources". ${ }^{1}$ Quality improvement is "the framework we use to systematically improve the ways care is delivered to patients". 2 Patient safety is defined by World Health Organization (WHO) as 
the absence of preventable harm to a patient during the process of health care and reduction of risk of unnecessary harm associated with health care to an acceptable minimum. $^{3}$

Over the past 2 decades, several healthcare-related transformative changes occurred that included restructuring medical education to meet quality improvement and patient safety priorities (QIPS). ${ }^{4,5}$

Accordingly, QIPS competencies requirements were made mandatory for residency training programs by the Accreditation Council for Graduate Medical Education (ACGME) and Canadian Medical Education Directives for Specialists (CanMEDS). ${ }^{6,7}$ Even though QIPS education is considered relatively new, many healthcare organizations and policymakers recognized the benefits of training clinicians in QIPS; therefore, QIPS education became a central component of many healthcare education curricula in undergraduate and postgraduate programs. ${ }^{8}$

Residency training is a postgraduate medical education in a specialty that provides the residents with clinical experience and education to be independent practitioners. ${ }^{9}$ Initiatives to improve resident training in general include redesigning residency training programs, planning pedagogical solutions, training of the trainers, and stress coping skills support. ${ }^{10,11}$

Since residents play a central role in the patient care, training programs must actively incorporate education in QIPS into the training program curriculum. ${ }^{12,13}$ Training in quality improvement during the residency will allow residents to develop the necessary skills to deliver highquality patient care. ${ }^{14}$ Furthermore, residents are the future consultants who carry the primary responsibilities of quality of care and patient safety. Therefore, residency training programs must have an impactful, relevant learning experience. ${ }^{15}$ Initiatives to enhance residents training in QIPS include dedicated education time, support from hosting institutes, faculty mentorship, regulation of residents' duty hours, and simplification of safety event reporting. ${ }^{15-17}$

There are also several options identified in the literature to design a QIPS curriculum for residents. They include

web-based modules, self-directed reading, workshops, work with quality coaches, project champions, small group work, quality improvement project, chart audits, and case discussions during morbidity and mortality conference. $^{12}$
Chart audits, root cause analysis, and involvement in QIPS initiatives were found to be the most common quality improvement projects. $^{18}$ Active education in QIPS is essential since passive participation is unlikely to produce a significant impact. ${ }^{19}$ Some of the recommended instructional methods to teach quality improvement in residency training include cases-based learning and experiential learning using a systematic approach. These methods will empower the residents to be the future quality improvement and patient safety leaders and positively impact the quality of care and safety during residency. ${ }^{20,21}$

Saudi Commission for Health Specialties (SCFHS) is the regulatory body that oversees postgraduate medical education in Saudi Arabia. SCFHS included education in QIPS as a requirement for the residency training programs recognition and the institutes' accreditation standards. ${ }^{22}$ Internal Medicine Residency Training Program, under the SCFHS, adopted CanMEDS framework for curriculum development with modifications to address contexts in Saudi Arabia, and the requirement to gain competencies in QIPS by the residents was maintained. ${ }^{23,24}$

The challenges and barriers for the implementation of QIPS curriculum in post-graduate medical education were identified in literature and included lack of dedicated time, lack of prioritizing quality improvement and patient safety activities due to competing priorities, lack of faculty experience or capacity for supervising and mentoring, lack of trainee's engagement, lack of support from the institute, lack of continuous training, lack of seeing the connection between evidence-based medicine and quality improvement and absence of competence evaluation using a consistent system. ${ }^{15,25,26}$ Limited information from Saudi Arabia on how QIPS education is incorporated in the internal medicine residency training programs. This information is vital for further research and for improvement initiatives.

The objectives of this study were to explore the residents' understandings of QIPS concept, perceptions of their role in QIPS, value of QIPS education for them, barriers and opportunities, and experience with internal medicine residency curriculum related to QIPS education.

To the best of our knowledge, no such study was conducted in postgraduate medical education in Saudi Arabia. The findings of this study will contribute to advancing QIPS training in residency training.

\section{Method}

This was an exploratory qualitative study employing grounded theory method. ${ }^{27}$ The study protocol was 
approved by the Institute Research Board (IRB) at King Abdullah International Medical Research Center (Reference Number IRBC/1478/20). The study was conducted at King Abdulaziz Hospital, Ministry of National Guard Health Affairs. It is a 260-bed tertiary hospital at Al Ahsa, Saudi Arabia, hosts residency training programs in primary specialties, including internal medicine. It has been accredited by Joint Commission International (JCI) and the Central Board for Accreditation of Healthcare Institutions (CBAHI). The Saudi Commission for Health Specialties (SCFHS) has also recognized it as a residency training center in internal medicine since 2005. At the time of this study, there were 35 residents and 38 consultant trainers. The program is managed by a residency training program director and his deputy. Chief resident represents residents in the residency training committee, which oversees the educational process. The program is a competency-based 4-year structured clinical training program. The residents $(\mathrm{R})$ are classified according to their residency year (1-4) as first year (R1), second year (R2), third year (R3) and fourth year (R4).

The first year (R1) and second year (R2) are a junior level, while the third (R3) and fourth (R4) are a senior level. During training, the residents rotate to different areas as required by the structured program. Competence assessment is composed of ongoing monthly evaluation by the trainer, yearly promotion exam, first part exam after the second year, and final exam after the fourth year. The program graduates are awarded a Saudi board certificate in internal medicine after completion of the fourth year and passing the exam.

All the 35 residents were eligible to participate in this study and were recruited using a purposeful sampling strategy. The residents were selected for interview one by one starting from the top of a list which was already available in the program. Balance in residents' level and gender was maintained. The sample size was determined using the theoretical saturation point, at which additional interviews stop providing new insights into the questions being explored.

\section{Data Collection}

Semi-structured individual interviews were utilized for data collection. The interview questions were developed based on the literature review, participants' opinions, and experts input. They were then piloted on five participants. The nine interview questions and probes are presented in the interview guide (Figure 1). The corresponding author who conducted the interviews received online training on conducting individual interviews for a qualitative study. Residents were familiar with him as a consultant endocrinologist who used to be involved regularly in residency training activities. The selected participant was sent an email invitation with an introduction to the study and a copy of the approved informed consent which stated agreement for participation, to record and to transcribe responses. Also, it stated that responses will be kept anonymous and used for the study purpose only. Once a resident accepted to participate, an interview was arranged. All the individual interviews took place between September 6 and October 20, 2020; each interview took 30-45 minutes face to face.

The interviews were conducted in an office in the medical services and only the interviewer and interviewee attended. The interview was started by introducing the study's purpose since familiarity and rapport between the interviewer and participants were already established. However, to minimize the influence of the relationship power between the interviewer and the participants and to establish norms and open communication during the interview, explicit disclosure of the purpose of the interview, role of the interviewer in the context of the study, reassurance of the confidentiality and freedom to participate or not without consequences or even to withdraw at any time were made clear during the introduction. In addition for the same purpose, continuous self-awareness and reflexive approach were maintained throughout the process with review of the transcribed interviews by the other research team members and feedback in regular meetings.

After obtaining the written informed consent and permission, the interviews were audio-recorded then trantranscribed verbatim. The participants were encouraged to provide a thorough description of their experience. Different probing strategies were used to obtain in-depth data, while extreme caution was made to avoid leading questions. Notes taken during the interview were reviewed with the participant to confirm the intended meaning. Upon concluding the meeting, the participants were asked if they wanted to add other information. No personal identifying data were collected. The interview transcript contained demographic data only and a study serial number linked to the residents' list, which was kept separately. The number of interviews went beyond theoretical saturation to reassure sufficient study aim coverage. No financial incentive or other incentive was provided to the resident to 
Welcome and Introduction

1.What do quality improvement and patient safety mean to you?

2.Explain your role in quality improvement and patient safety?

Probe: Why do you think it is important?

3.Describe the value of quality improvement and patient safety education for you during residency training?

Probe: Why do you think it is of value to you?

4. How do you get educated in quality improvement and patient safety during residency training?

Probe: What do you think about the following activities in relation to your education in quality Improvement and patient safety?

1. Orientation upon joining the program

2. Medication safety course

3. Infection prevention course

4. Direct supervision of residents by consultants

5. Incident reports review

6. Quality improvement project

7. Mortality and morbidity review

8. Annual quality and patient safety day

9. Implementation of evidence-based medicine

10. Multidisciplinary patient care meeting

11. Handover

12. Monthly rotation evaluation form

13. Simulation

14. Educational webinar

15. Online Universal topics

16. Inclusion of quality improvement and patient safety in exam

5.What are the activities you have participated in to gain education about quality improvement and patient safety?

6.What are the opportunities for education in quality improvement and patient's safety?

Probe: What opportunity that you think you can participate in to gain knowledge and experience?

7.How is your competence in quality improvement and patient safety assessed?

Probe: Do you recall QIPS assessment by written exam, clinical exam or by other form?

8. What are the barriers for quality improvement and patient safety education?

Probe: If you would like to be trained in QIPS what difficulties will face you?

9. What do you suggest for improving education in quality improvement and patient safety?

Probe: What changes that you may propose to make QIPS education better?

Closure: anything to add relevant to quality improvement and patient safety education?

Figure I Interview guide, the questions and probes that were used for the semi-structure interviews.

participate; however, they were thanked at the end of the interview and sent thanks email post-interview.

\section{Data Analysis}

The constructivist grounded theory with the inductive approach was followed for analysis as described by Kathy Charmaz. ${ }^{27,28}$ The analysis was ongoing throughout the data collection period and continued afterward. The interviews transcripts were read and re-read repeatedly to gain full familiarity with the information. The study objectives were revisited regularly to keep them under focus while themes and concepts emerged. The corresponding author did all codings, which were reviewed and confirmed independently by the other three authors. Constant comparison and iteration were implemented to identify emerged themes in all stages of analysis. Each team member used to be sent an electronic copy of the updated analysis for an independent review. Then the research team used to have a weekly online meeting to review and debate findings. All the research team members agreed on the final findings.

Reflexive diaries were kept digitally throughout the study process to enhance reflexivity. They were reviewed in the context of the interpretation of the data and reflected upon regularly. Also, items pertinent to data analysis from the 32 items of standards for reporting qualitative research (SRQR) were utilized as a checklist. ${ }^{29,30}$ 
The final findings were sent back to the participants, who accepted them with no further comments. The findings were reviewed and contrasted to the transcribed interviews by a colleague who was not involved in the study, and she confirmed the appropriateness of the findings. Besides, the findings were checked against program documents available at the SCFHS website with open access, which included the curriculum mapping and the exam blueprints. ${ }^{31-34}$

\section{Results}

Twenty-two residents (including the five participants in the pilot phase) were needed to serve the study questions (Table 1). The emerged themes are presented under the following domains supported by quotes from the participants' interviews.

\section{Awareness}

Residents perceived the meaning of quality improvement as providing the best for the patient and patient safety as providing benefit and avoiding harm. A fourth year 34-year-old male resident explained, "Aiming for the best for the patient."

The residents' role was perceived as priority to see patient and engagement in the health system. A third year 31-yearold male resident commented: "We are part of the system, and we need really to be part of the quality team." The residents valued QIPS education as basic for capacity building for future consultants. A third year 29-year-old male resident noted, "It is the time for me to learn quality improvement and patient safety as I will be a consultant."

\section{Education}

Residents perceived lack of formal dedicated specific QIPS education under the residency training program. A fourth year 29-year-old female resident commented, "I do not remember any training under the program." However, activities like orientation at the beginning of the residency, medication safety

Table I Study Participants

\begin{tabular}{|l|c|c|c|}
\hline \multirow{2}{*}{ Training Level } & \multicolumn{2}{|c|}{ Gender } & \multirow{2}{*}{ Total Number } \\
\cline { 2 - 3 } & Male & Female & \\
\hline First-year resident & 2 & 3 & 5 \\
Second-year resident & 3 & 2 & 5 \\
Third-year resident & 3 & 3 & 6 \\
Fourth-year resident & 3 & 3 & 6 \\
Total & 11 & 11 & 22 \\
\hline
\end{tabular}

course, patient care under the consultants' supervision, annual quality and patient safety day, multidisciplinary patient care meetings, patient handover, evidence-based medicine implementation, and online universal topics were perceived as QIPS education. Participation in incident reports review, quality improvement project, mortality and morbidity review, simulation and educational webinar were lacking.

Assessment was by direct supervision by consultant and feedback. A third year 29-year-old, female resident noted, "I think the only thing is by consultant's supervision, and they will evaluate us by the end of the month." The residents recognized 2-5 questions per 100 MCQS relevant to QIPS in the annual promotion written exam; however, they did not recognize any in clinical exam which is conducted yearly as an Objective Structured Clinical Examination (OSCE).

\section{Opportunities and Barriers for QIPS Education}

Review of the morbidity and mortality cases, review of the incident reports and participation in quality improvement projects were perceived as opportunities.

Barriers include, time constrains due to patient care and due to other competing tasks, eg, preparation for the exam. A second year 26-year-old female resident explained, "We are usually busy with a patient, doing procedures and preparing for the exam." Another barrier was the lack of integration between the residency training program and hospital QIPS activities. A fourth year 29-year-old, male resident commented, "Training is separate from quality improvement and patient's safety department, must be linked together, it should be part of each other." Lack of experts in QIPS training was also perceived as a barrier.

\section{Improvement Priorities}

Creation of mandatory QIPS education component of the curriculum was suggested. A first year 26-year-old, male resident indicated, "I feel it is mandatory because it is important.". A course in the beginning of residency and a QIPS rotation were recommended. A second year 27-year-old female resident noted, "rotation is an excellent idea so that it will be formal, and the rotation will make sure the resident will learn."

\section{Discussion}

This study aimed to explore educational aspects of quality improvement and patient safety (QIPS) in the Internal 
Medicine Residency Training Program at King Abdulaziz Hospital.

The aim of the study was achieved through semistructured individual interviews. The residents showed a shared mental model about the quality improvement concept as offering the best to patients and patient safety concept as providing benefit and avoiding harm. This understanding is relevant to the definition of quality improvement and patient safety. ${ }^{2,3}$ This finding contrasts previous report where residents' diversity and inconsistency of QIPS understanding were found. ${ }^{35}$

The residents perceived the high importance of their role in QIPS, which was attributed to their function to serve the patient as front liners and their engagement in the healthcare system. The residents highly valued QIPS education as essential for building future consultants who improve patients' outcomes. This finding was consistent with the previous studies wherein residents felt that quality improvement influences current and future practices. ${ }^{36}$ These important findings reflect the relatively recent big move in Saudi Arabia to optimize the quality of care and patient safety. Accreditation of healthcare institutions in Saudi Arabia became mandatory in $2013 .{ }^{37}$ A relatively recent cross-sectional questionnaire-based study from Saudi Arabia showed $>90 \%$ of residents from different specialties were aware of international patient safety goals. ${ }^{38}$ The residents did not recognize specific dedicated QIPS educational components under the structured internal medicine residency training program curriculum, despite their participation in several QIPS activities. This discrepancy is likely because such activities were embedded during training without allocating them under specified QIPS educational component under the program curriculum. The residents feeling that quality improvement is not directly part of the training program was also observed in another study which is consistent with our finding. ${ }^{35}$

Most of the activities mentioned by residents were passive, like medication safety course, patient safety orientation, and infection prevention course. These activities, in addition to handover, were also patient safety-oriented rather than addressing quality improvement principles. Such observation was reported in the literature previously since participation may positively influence attitude to QIPS, however, unlikely to significantly impact education. $^{15,19}$

Participation in activities like quality improvement projects, incident report review, mortality, and morbidity review were lacking. These activities, in particular, quality improvement projects, are considered an opportunity for active learning of quality improvement principles. A relatively recent survey showed only two-thirds of the residents participated in quality improvement activities, which was considered low in a family medicine residency training programs that has made efforts to integrate them. ${ }^{36}$ Participants in this study recognized QIPS competence assessment by written exam and direct observation by the consultants during patient care. The curriculum mapping did not include an assessment of QIPS competence; however, the final written exam blueprint included patient safety but not quality improvement. The objective structured clinical examination (OSCE) blueprints also included patient safety without quality improvement. ${ }^{31-34}$ Lack of system for competency assessment in QIPS was identified as a challenge in literature, although there are well-studied tools for assessment of quality improvement education effectiveness, one of them is the Quality Improvement Knowledge Application Tool - Revised, which is well established. ${ }^{26,39}$

There were three opportunities for QIPS learning recognized by residents, review of morbidity and mortality cases, review of the incident report, participation in quality improvement projects. These opportunities were recognized in the literature for teaching QIPS to trainees. ${ }^{13}$ Furthermore, important barriers to QIPS education were found that include time constraints and other competing duties, which is are consistent with other studies. ${ }^{34,39}$ The time pressure in residency training was highlighted in a recently published study from an internal medicine residency training program, Riyadh, Saudi Arabia, which found that the increasing number of patients was the main source of time pressure. ${ }^{40}$ Lack of integration between QIPS and the training program is another barrier highlighted by residents. This observation is congruent with previous studies as residents felt a separation between quality improvement and the patient care setting where they received training. ${ }^{15,34}$ Participants also recognized a lack of expert trainers as another QIPS education barrier, which is well documented in literature..$^{35,41}$

Improvement priorities that were indicated by residents included making QIPS education a mandatory component of the training program as a rotation and a course at the beginning of residency. These suggestions reflect the residents' awareness of the importance of QIPS education and their need to have it formally in the program. A simulation was perceived to improve patient safety by $84 \%$ of the trainees and $100 \%$ of the trainers in a multicenter cross- 
sectional questionnaire-based survey in surgical residency training programs in Saudi Arabia. ${ }^{42}$

\section{Limitation}

Limited generalizability was due to the inherent generalizability limitation in qualitative studies in general. In addition, this study was limited to a single institute and to one specialty residency training program, ie, internal medicine, so we do not know about other programs and institutes. This study was limited to the trainee's perspectives; therefore, other stakeholders' perspectives like the trainers were not explored.

\section{Strength}

Our study addressed an important area in postgraduate medical education related to patient safety and quality improvement. It will open the gate for further studies and initiatives to improve QIPS education in residency training programs.

\section{Conclusion}

This study highlighted awareness of internal medicine residents of QIPS concept and the value of its education. Gaps related to curriculum design, delivery of education and barriers were found consistent with findings reported in literatures. One of the improvement priorities identified was making QIPS education a mandatory component of the residency training program curriculum. Up to our best knowledge, this is the first study from Saudi Arabia in this area and should lay the foundation for further research and improvement. We recommend further studies to verify our findings and measure the range of gaps. It is also an opportunity for the leaders and policymakers of health organizations that host postgraduate training programs in Saudi Arabia to invest in QIPS education as an essential component of postgraduate training to enhance the quality of care and patient safety.

\section{Acknowledgments}

The authors wanted to thank all the internal medicine residents trainees in King Abdulaziz Hospital, Al Ahsa, Saudi Arabia who participated in this study, and the internal medicine residency training program management team. Dr Maram Alsubaiee for peer-reviewing the findings. Also they would like to express their gratitude to King Abdullah International Medical Research Center for the support and issuing approval by the IRB and to Ministry of National Guard Health Affairs for facilitating the execution of the study at the King Abdulaziz Hospital, Al Ahsa, Saudi Arabia.

\section{Disclosure}

The authors reported no conflicts of interest for this work.

\section{References}

1. Wong R. Teaching quality improvement in residency education.: Royal College of Physicians and Surgeons of Canada; 2015.

2. Agency for Healthcare Research and Quality. Approaches to quality improvement; 2013. Available from: https://www.ahrq.gov/ncepcr/ tools/pf-handbook/mod4.html. Accessed November 1, 2020.

3. World Health Organization. Patient safety. Available from: https:// www.who.int/patientsafety/en/. Accessed October 7, 2020.

4. Institute of Medicine (US) Committee on Quality of Health Care in America. To Err is Human: Building a Safer Health System. Kohn LT, Corrigan JM, Donaldson MS, editors. Washington (DC): National Academies Press (US); 2000.

5. Institute of Medicine (US) Committee on Quality of Health Care in America. Crossing the quality chasm: a new health system for the 21st century. Washington (DC): National Academies Press (US); 2001. Executive Summary. Available from: https://www.ncbi.nlm. nih.gov/books/NBK222271/. Accessed April 19, 2021.

6. Accreditation Council for Graduate Medical Education. ACGME common program requirements; 2017. Available from: https://www. acgme.org/portals/0/pfassets/programrequirements/cprs_2017-07-01. pdf. Accessed October 7, 2020.

7. Frank JR, Snell L, Sherbino J, editors. CanMEDS 2015 Physician Competency Framework. Ottawa, ON: Royal College of Physicians and Surgeons of Canada; 2015.

8. Jones B, Vaux E, Olsson-Brown A. How to get started in quality improvement. BMJ. 2019;364:k5408. doi:10.1136/bmj.k5437

9. The Accreditation Council for Graduate Medical Education (acgme). About Us; 2018. Available from: https://www.acgme.org/About-Us /Overview. Accessed November 25, 2020.

10. Meyers FJ, Weinberger SE, Fitzgibbons JP, Glassroth J, Duffy FD, Clayton CP. Alliance for academic internal medicine education redesign task force. redesigning residency training in internal medicine: the consensus report of the alliance for academic internal medicine education redesign task force. Acad Med. 2007;82(12):1211-1219. doi:10.1097/ACM.0b013e318159d010

11. Vilppu H, Murtonen M, Österholm E, Mikkilä-Erdmann M. 'How can the training of medical residents be improved? Three suggestions'. MedEdPublish. 2019;8(1):17. doi:10.15694/mep.2019.000017.1

12. Schumacher DJ, Frohna JG. Patient safety and quality improvement: a "CLER" time to move beyond peripheral participation. Med Educ Online. 2016;21:31993. doi:10.3402/meo.v21.31993

13. Fok MC, Wong RY. Impact of a competency-based curriculum on quality improvement among internal medicine residents. BMC Med Educ. 2014;28(14):252. doi:10.1186/s12909-014-0252-7

14. Courtlandt C, Noonan L, Koricke MW, Zeskind PS, Mabus S, Feld L. Pediatrics residents' confidence and performance following a longitudinal quality improvement curriculum. J Grad Med Educ. 2016;8(1):74-79. doi:10.4300/JGME-D-15-00032.1

15. Massagli TL, Zumsteg JM, Osorio MB. Quality improvement education in residency training: a review. Am J Phys Med Rehabil. 2018;97 (9):673-678. doi:10.1097/PHM.0000000000000947

16. Volpp KG, Rosen AK, Rosenbaum PR, et al. Mortality among hospitalized Medicare beneficiaries in the first 2 years following ACGME resident duty hour reform. JAMA. 2007;298(9):975-983. doi:10.1001/jama.298.9.975

17. Singal M, Godbole M, Zafar A, Jadhav N, Alweis R, Bhavsar H. Interventions to improve resident reporting of patient safety events: a quality improvement initiative. J Commun Hospital Internal Med Perspect. 2020;10:431-435. doi:10.1080/ 20009666.2020.1799494 
18. Jones AC, Shipman SA, Ogrinc G. Key characteristics of successful quality improvement curricula in physician education: a realist review. Postgrad Med J. 2015;91:102-113. doi:10.1136/postgradmedj-2014-002846rep

19. Wong BM, Levinson W, Shojania KG. Quality improvement in medical education: current state and future directions. Med Educ. 2012;46:107-119. doi:10.1111/j.1365-2923.2011.04154.x

20. Werner JA. An integrated, multimodal resident curriculum in patient safety and quality improvement. MedEdPORTAL. 2017;13. doi:10.15766/mep_2374-8265.10641

21. Morrison RJ, Bowe SN, Brenner MJ. Teaching quality improvement and patient safety in residency education: strategies for meaningful resident quality and safety initiatives. JAMA Otolaryngol Head Neck Surg. 2017;143(11):1069 1070. doi:10.1001/jamaoto.2017.1317

22. Saudi Commission for Health Specialities. Accreditation forms; 2017. Available from: https://www.scfhs.org.sa/en/education/Pages/ Default.aspx. Accessed October 8, 2020.

23. Saudi Commission for Health Specialties (scfhs). List of postgraduate programs; 2017. Available from: https://www.scfhs.org.sa/en/ MESPS/TrainingProgs/List\%20graduate\%20programs/Pages/default. aspx. Accessed May 12, 2020.

24. Amin Z, Alshammary S. CanMEDS curriculum in Saudi Arabian context: lessons learned and way forward. J Health Specialties. 2015;3:206-211. doi:10.4103/1658-600X.166500

25. Kirkman MA, Sevdalis N, Arora S, et al. The outcomes of recent patient safety education interventions for trainee physicians and medical students: a systematic review. BMJ Open. 2015;5:e007705. doi:10.1136/bmjopen-2015-007705

26. Mosser G, Frisch KK, Skarda PK, Gertner E. Addressing the challenges in teaching quality improvement. Am J Med. 2009;122 (5):487-491. doi:10.1016/j.amjmed.2009.01.013

27. Chun Tie Y, Birks M, Francis K. Grounded theory research: a design framework for novice researchers. SAGE Open Med. 2019;2 (7):2050312118822927.

28. Charmaz K. Constructing Grounded Theory (Introducing Qualitative Methods Series). 2nd ed. London: SAGE Publications Ltd; 2014.

29. Berger R. Now I see it, now I don't: researcher's position and reflexivity in qualitative research. Qual Res. 2015;15(2):219-234. doi: $10.1177 / 1468794112468475$

30. O'Brien BC, Harris IB, Beckman TJ, Reed DA, Cook DA. Standards for reporting qualitative research: a synthesis of recommendations. Acad Med. 2014;89(9):1-1245. doi:10.1097/ACM.0000000000000388

31. Saudi Commission for Health Specialties (scfhs). Mapping of internal medicine postgraduate curricular competencies with assessment too. Available from: https:/www.scfhs.org.sa/en/MESPS/TrainingProgs/ List \%20graduate\%20programs/Documents/CBA\%20Internal\% 20Medicine\%202020.pdf. Accessed November 22, 2020.
32. Saudi Commission for Health Specialties (scfhs). Saudi board final clinical examination of internal medicine (2020); 2020. Available from: https://www.scfhs.org.sa/en/MESPS/TrainingProgs/List\%20grad uate $\% 20$ programs/Documents/Internal $\% 20$ Medicine $\% 20 \% 20$ Clinical \%20Exam\%20Blueprint\%202020.pdf. Accessed November 24, 2020.

33. Saudi Commission for Health Specialties (scfhs). Saudi board residency training program internal medicine Final Written Examination; 2020. Available from: https://www.scfhs.org.sa/examinations/ TrainingExams/Documents/Internal\%20Medicine\%20Board-Final\% 20Exam\%20Blueprint.pdf. Accessed November 24, 2020.

34. Saudi Commission for Health Specialties (scfhs). Saudi board residency training program internal medicine promotion examination; 2020. Available from: https://www.scfhs.org.sa/en/MESPS/ TrainingProgs/List\%20graduate\%20programs/Documents/ INTERNAL\%20MEDICINE.pdf. Accessed November 24, 2020.

35. Butler JM, Anderson KA, Supiag no MA, et al. "It feels like a lot of extra work": resident attitudes about quality improvement and implications for an effective learning health care system. Acad Med. 2017;92:984-990. doi:10.1097/ACM.0000000000001474

36. Haggerty T, Lewis W, Plaugher C, et al. Residents' views on research and quality improvement training can guide practice-based research network collaboration. $W V$ Med J. 2018;2018. doi:10.21885/ wvmj.2018.14.

37. The Saudi Central Board for Accreditation of Healthcare Institutions (cbahi). Cbahi at a glance. 201. Available from: https://portal.cbahi. gov.sa/english/about-us/cbahi-at-a-glance. Accessed November 16, 2020.

38. Omer JA, Al-Rehaili OA, Al-Johani H, Alshahrani D. Residents' awareness about international patient safety goals, Cross-Sectional Study. Arch Pediatr. 2018;3:139.

39. Singh MK, Ogrinc G, Cox KR, et al. The Quality Improvement Knowledge Application Tool Revised (QIKAT-R). Acad Med. 2014;89:1386-1391. doi:10.1097/ACM.0000000000000456

40. Alqahtani DA, Mahzari MM, Alqahtani AA, Rotgans JI. Time pressure experienced by internal medicine residents in an Educational Hospital in Saudi Arabia: a Qualitative Study. Health Professions Edu. 2020;6(3):354-367. doi:10.1016/j.hpe.2020.05.005

41. Wong BM, Etchells EE, Kuper A, Levinson W, Shojania KG. Teaching quality improvement and patient safety to trainees: a systematic review. Acad Med. 2010;85(9):1425-1439. doi:10.1097/ACM.0b013e3181e2d0c6

42. Alotaibi NH, Oker N, Zafar M, Al-Qahtani KH, Higham H. Surgical training in Saudi Arabia: trainees' perspectives and the role of simulation. Int J Surg Open. 2015;1:1-4. doi:10.1016/j.ijso.2015.08.001
Advances in Medical Education and Practice

\section{Publish your work in this journal}

Advances in Medical Education and Practice is an international, peerreviewed, open access journal that aims to present and publish research on Medical Education covering medical, dental, nursing and allied health care professional education. The journal covers undergraduate education, postgraduate training and continuing medical education including emerging trends and innovative models linking education, research, and health care services. The manuscript management system is completely online and includes a very quick and fair peer-review system. Visit http://www.dovepress.com/testimonials.php to read real quotes from published authors. 